\title{
Effects of Ovarian Steroids and Raloxifene on Proteins that Synthesize, Transport, and Degrade Serotonin in the Raphe Region of Macaques
}

\author{
Lisa J Smith', Jessica A Henderson', Creed W Abell ${ }^{4}$ and Cynthia L Bethea*, 1,2,3 \\ 'Division of Reproductive Sciences, Oregon National Primate Research Center, Beaverton, OR, USA; 2Division of Neuroscience, Oregon National \\ Primate Research Center, Beaverton, OR, USA; ${ }^{3}$ Department of Physiology and Pharmacology, Oregon Health and Science University, Portland, \\ OR, USA; ${ }^{4}$ Institute of Neuroscience, University of Texas, Austin, TX, USA
}

\begin{abstract}
In the monkey dorsal raphe, we reported that I-month (mo) of estrogen replacement, with or without progesterone supplementation for 14 days, significantly increased tryptophan hydroxylase- I (TPH-I) mRNA; decreased serotonin reuptake transporter (SERT) mRNA and decreased monoamine oxidase (MAO)-A mRNA, but had no effect on MAO-B mRNA. Here, we questioned what effect would I or 5 mo of ovarian hormones or the selective estrogen receptor modulator (SERM), raloxifene, have on TPH protein and phosphorylation, and on protein expression of SERT, MAO-A or MAO-B? Raloxifene antagonizes estrogen in breast or uterus, but estrogen-like activities in the brain have been reported. Cytoplasmic and membrane extracts of the dorsal raphe region were processed for Western blotting. TPH, phosphoserine, SERT, MAO-A, and MAO-B were detected with specific antibodies. The optical densities of the signals were measured with NIH image and analyzed by ANOVA. Both I and 5 mo of estrogen, with or without progesterone, and 5 mo of raloxifene significantly increased TPH protein. Administration for 5 mo of estrogen plus progesterone and raloxifene also increased TPH phosphorylation. Estrogen, with or without progesterone, for I mo had no effect on SERT protein. However, 5 mo of estrogen and 5 mo of raloxifene increased SERT protein. Estrogen alone or combined with progesterone for I mo caused a significant reduction in MAO-A. Yet, after 5 mo of the same treatments, MAO-A was not different from spayed controls. Estrogen alone had no effect on MAO-B. However, the addition of progesterone significantly increased MAO-B. Raloxifene for 5 mo had no effect on MAO-A or MAOB. Thus, to various extents, estrogen, progesterone, and raloxifene may increase serotonin production and transport. The expression of the degradative enzymes suggests a complex combination of gene transcription, post-transcriptional processing, and substrate feedback mechanisms.

Neuropsychopharmacology (2004) 29, 2035-2045, advance online publication, 16 June 2004; doi: I0.1038/sj.npp. 13005 I 0
\end{abstract}

Keywords: serotonin; macaques; tryptophan hydroxylase; phosphorylation; monoamine oxidases; reuptake transporter; Western blots; estrogen; progesterone; raloxifene; selective estrogen receptor modulator; SERM

\section{INTRODUCTION}

Serotonin is now recognized as playing a regulatory role in an ever-growing number of autonomic functions (Dedeoglu and Fisher, 1994), cognitive domains (Meneses, 1999), affective, anxiety, and stress-related disorders (Lesch et al, 1996; Shively et al, 1997; Clement and Chapouthier, 1998; Shively et al, 2003), and even metabolic syndromes (Muldoon et al, 2004). As such, the serotonin neural system is a target of pharmacotherapies, steroid hormones, cytokines, neuropeptides, and growth factors, all of which

\footnotetext{
*Correspondence: Dr CL Bethea, Oregon National Primate Research Center, 505 NW 185th Ave., Beaverton, OR 97006, USA, Tel: + I 503690 5327, Fax: + I 503690 5384, E-mail: betheac@ohsu.edu Received 28 January 2004; revised I April 2004; accepted 12 May 2004 Online publication: 17 May 2004 at http://www.acnp.org/citations/ Npp05 $170404039 /$ default.pdf
}

impact the generation and efficacy of serotonin neurotransmission. The most frequent serotonin pathology is depression, and this disorder exhibits gender bias (Weissman and Olfson, 1995). A long-standing issue in psychiatry has been whether this gender bias may have a neurobiological underpinning (Schwartz, 1991; Williams et al, 1995).

This laboratory has devoted effort toward understanding the actions of ovarian hormones in serotonin neurons and their terminal fields with a macaque model of surgical menopause. We found that estrogen regulates the expression of pivotal serotonin-related genes in a pattern suggestive of increased serotonin production, increased neural firing, and decreased degradation (Bethea et al, 2002a). Recently, we determined that protein expression proceeds from and/or reflects gene expression for $5 \mathrm{HT} 1 \mathrm{~A}$ receptors, but not for SERT, the serotonin reuptake transporter (SERT) (Lu and Bethea, 2002; Lu et al, 2003). That is, 5HT1A gene expression and $\left[{ }^{3} \mathrm{H}\right] 8-\mathrm{OH}-\mathrm{DPAT}$ binding to the 
5HT1A receptor are both decreased by estrogen. Paradoxically, SERT mRNA decreased with estrogen treatment, but $\left[{ }^{3} \mathrm{H}\right]$ citalopram binding to the transporter was unchanged in the raphe, and SERT trafficking to forebrain axons actually increased. Here, we extend this line of investigation to tryptophan hydroxylase (TPH) and the monoamine oxidases A and B (MAO-A and -B). In addition, SERT protein was examined for comparison to previous $\left[{ }^{3} \mathrm{H}\right]$ citalopram-binding studies.

$\mathrm{TPH}$ is the rate-limiting enzyme for the synthesis of serotonin and TPH protein is translated from two mRNA transcripts, TPH-1 and TPH-2, with a large degree of homology in the coding regions (Walther et al, 2003). Commercially available antibodies do not discriminate between the translated proteins and provide an indication of total TPH. We demonstrated that 1 month (mo) of estrogen, with or without supplemental progesterone, increased TPH-1 mRNA levels in the dorsal raphe of macaques (Pecins-Thompson et al, 1996). Recently, we have found that $\mathrm{TPH}-2$ is regulated in a similar manner (unpublished). Ovarian hormone replacement for 1 mo also increased total TPH protein in a manner reflecting gene expression (Bethea et al, 2000). Although 1 mo of treatment is considered quite long in rodent experimentation, human subjects generally take hormone replacement for even longer periods. In this study, we compared longer treatment with estrogen or estrogen + progesterone to our standard 1-mo protocol on the expression of TPH protein. Moreover, TPH requires phosphorylation for activity and this step could be differentially regulated from protein synthesis. Therefore, we also examined the phosphorylation of TPH in different treatment groups using an antibody to phosphoserine.

The SERT plays a pivotal role in the regulation of extracellular serotonin levels and it is the primary target of the class of antidepressants known as selective serotonin uptake inhibitors or SSRIs. The regulation of SERT is not intuitive. SERT is thought to remove serotonin from the synapse but clinically, there is evidence that the expression of SERT protein is elevated in conditions when serotonin is elevated (Lawrence et al, 1990). In macaques, SERT as detected by $\left[{ }^{3} \mathrm{H}\right]$ citalopram binding was elevated in forebrain regions, but not the raphe after 1 mo of estrogen treatment (Lu et al, 2003). However, SERT detected with Western blotting was elevated in the raphe region after 2 years of estrogen treatment (Shively et al, 2003). We sought the level of SERT protein on Western blot after 1 mo of hormone treatment to compare to the previous $\left[{ }^{3} \mathrm{H}\right]$ citalopram-binding results and after 5 mo of hormone treatment to observe a time point intermittent between 1 mo and 2 years.

MAOs degrade serotonin and catecholamines (Von Korff, 1979; Fowler and Tipton, 1982; Shih et al, 1999; Abell and Kwan, 2001) The MAO inhibitors were among the first antidepressants used clinically, indicating that decreases in degradation can benefit serotonin transmission (Celada et al, 1992). We showed that 1 mo of ovarian hormone replacement decreased gene expression for MAO-A in the dorsal raphe region, and decreased both MAO-A and MAO$B$ gene expression in regions of the hypothalamus (Gundlah et al, 2001a). Therefore, in this study we examined the effects of estrogen, with and without progesterone supplementation, on protein expression of MAO-A and MAO-B in the dorsal raphe region and compared the 1-mo treatment period to a 5-mo treatment period.

Various formulations of estrogens and progestins are available for hormone replacement therapy (HRT) after menopause. The different formulations of estrogen appear to benefit aspects of CNS function in various animal models (Gibbs, 2000; Wise et al, 2001; Bethea et al, 2002a) and in a few clinical studies (Schneider et al, 1997; Roof and Hall, 2000; Schmidt et al, 2000; Newhouse et al, 2002). However, recent reports have indicated that any formulation of HRT increases peripheral cancer risk (Chlebowski et al, 2003; Kerlikowske et al, 2003). Thus, there is a need for estrogenic ligands that benefit the CNS without the need for supplemental progestins and that do not have a peripheral risk profile. Providing proof of the principle that an SERM has estrogen-like benefits in the serotonin system could encourage further research and development in this area. We previously reported that raloxifene (Evista, Eli Lilly, Indianapolis, IN), a SERM that acts as an ER $\alpha$ antagonist and exhibits little action in the breast or uterus, increased TPH-1 mRNA expression in macaques (Bethea et al, 2002b). In this study, we questioned whether raloxifene would also increase TPH at the protein level and whether raloxifene would affect the expression of SERT, MAO-A, and MAO-B proteins.

\section{MATERIALS AND METHODS}

The Institutional Animal Care and Use Committee of the Oregon National Primate Research Center approved each experimental protocol. All monkeys were euthanized according to procedures recommended by the Panel on Euthanasia of the American Veterinary Association. Unless otherwise stated, reagents were ordered from Sigma Chemical Co., St Louis, MO. A total of 24 adult female (5-16 years old, $4-7 \mathrm{~kg}$ ) rhesus macaques (Macaca mulatta) were used.

\section{Animals and Experimental Groups}

The rhesus monkeys were sedated with ketamine $\mathrm{HCl}$ $(10 \mathrm{mg} / \mathrm{kg}$ i.m.) and then anesthetized deeply with pentobarbital (30 mg/kg i.v.). The brain, without perfusion, was removed from the cranium and the midbrain (from the rostral to the caudal border of the pons) was dissected, wrapped in foil, and immediately dropped in liquid nitrogen, then stored at $-80^{\circ} \mathrm{C}$ until sufficient numbers of animals were collected to warrant Western analysis. The time from cutting the diaphragm (cessation of oxygen to the brain) and freezing of the midbrain was in the order of $10 \mathrm{~min}$. Each necropsy was performed in a routine and consistent manner.

The rhesus monkeys were treated as follows:

(1) Spayed - adult females were ovariectomized and hysterectomized for 3-6 mo.

(2) Estrogen treatment for $1 \mathrm{mo}$-adult females were spayed for $3 \mathrm{mo}$ and then treated for 28 days with a $4.5 \mathrm{~cm}$ estradiol-filled Silastic capsule implanted subcutaneously in the periscapular region.

(3) Estrogen + progesterone treatment for 1 mo-adult females were spayed for 3 mo and then treated for 28 
days with a $4.5 \mathrm{~cm}$ estradiol-filled capsule supplemented with a $6.0 \mathrm{~cm}$ progesterone-filled capsule from days 14 to 28 , both implanted subcutaneously.

(4) Estrogen treatment for $5 \mathrm{mo}$ - adult females were spayed for 3 mo and then treated for 5 mo with a $4.5 \mathrm{~cm}$ estradiol-filled capsule implanted subcutaneously.

(5) Estrogen + progesterone treatment for 5 mo-adult females were spayed for 3 mo and then treated for 5 mo with a $4.5 \mathrm{~cm}$ estradiol-filled capsule and with a $6.0 \mathrm{~cm}$ progesterone-filled capsule implanted subcutaneously.

(6) Raloxifene treatment for $5 \mathrm{mo}$-adult females were spayed for 3 mo and then treated for 5 mo with raloxifene in a diet treat with the morning feed (07000800). The dose of raloxifene administered equaled $5 \mathrm{mg} / \mathrm{kg}$ body weight daily.

\section{Midbrain Dissection and Protein Assay}

The dissected midbrain block displayed the rounded central canal on its anterior surface and the wing-shaped canal on its caudal surface. This section was microdissected and a small square piece of tissue was harvested that extended from the middle of the central gray (cutting through the middle of the canal) to, but not including, the decussation of the cerebellar peduncles. The piece was the width of the central gray, and contained the major portion of the dorsal raphe (approximately $5 \mathrm{~mm}$ wide, $6 \mathrm{~mm}$ high, and $3 \mathrm{~mm}$ thick). Each piece was immediately homogenized in $1 \mathrm{ml}$ of $50 \mathrm{mM}$ Tris ( $\mathrm{pH}$ 7.5; ICN Biomedicals, Aurora, OH) and $20 \mathrm{mM} 2-\beta$-mercaptoethanol and centrifuged at $12000 \mathrm{~g}$ for $10 \mathrm{~min}$. The supernatant was removed and stored at $-80^{\circ} \mathrm{C}$ until Western blot analysis. Immediately prior to loading the gel, protein assays were performed on the supernatant with the Bio-Rad protein determination reagent according to the method of Bradford (1976).

\section{Western Analysis}

Phosphoserine and TPH. The raphe extracts containing $300 \mu \mathrm{g}$ of protein were loaded onto a $10 \%$ SDS-polyacrylamide gel. Aliquots of a large homogenate of monkey pineals were maintained at $-80^{\circ} \mathrm{C}$. The same volume and protein concentration $(129 \mu \mathrm{g})$ of pineal homogenate was included on each gel as a positive control. Molecular weight markers (Kalidescope, Biorad) were also included. Western blotting was performed according to the modified procedures of Dumas et al (1989) with blotting buffer containing $25 \mathrm{mM}$ Tris base (ICN) and $192 \mathrm{mM}$ glycine. The nitrocellulose membrane was initially stained with $2 \%$ Ponceau-S to display multiple bands in the sample lanes. The lane containing the molecular weight markers was cut from the membrane and the sample lanes were processed further.

The nitrocellulose membrane (Schleicher \& Schuel, Keene, $\mathrm{NH}$ ) containing the sample lanes was blocked with $5 \%$ aqueous Carnation nonfat dry milk (Nestle Food Company, Glendale, CA) for $45 \mathrm{~min}$. Rabbit anti-phosphoserine polyclonal antibody (Chemicon, Temecula, CA) was used at a dilution of $1 / 500$ in a buffer containing $50 \mathrm{mM}$ Tris and $150 \mathrm{mM} \mathrm{NaCl}(\mathrm{pH}$ 7.5). Goat anti-rabbit antibody conjugated with horseradish peroxidase (Chemicon) was used as second antibody at a dilution of $1 / 7000$ in $8 \%$ nonfat milk. A phosphoserine signal was detected by exposing the blot to chemiluminescent film after developing with Supersignal substrate reagents (Pierce, Rockford, IL). Scientific imaging film (Eastman Kodak, Rochester, NY) was used for the development of the signal.

The blot was then stripped for $15 \mathrm{~min}$ in $1 \times$ Re-Blot Plus Mild (Chemicon) and further incubated in affinity purified sheep anti-TPH (Chemicon) used at a dilution of 1/500 in a buffer containing $50 \mathrm{mM}$ Tris and $150 \mathrm{mM} \mathrm{NaCl}$ ( $\mathrm{pH} 7.5$ ). Rabbit anti-sheep antibody conjugated with horseradish peroxidase (Chemicon) was used as second antibody at a dilution of $1 / 3000$ in $5 \%$ nonfat milk. TPH signal was detected by exposing the blot to chemiluminescent film as above.

MAO-A and MAO-B. Never-thawed aliquots of all of the homogenates were run on new gels for determination of MAO-A and MAO-B. On each gel, in addition to the pineal control, purified aliquots of MAO-A and MAO-B were run as further positive controls. The proteins were transferred onto a nitrocellulose blot as described above. The blot was processed as described above, but first developed with a mouse monoclonal antibody to MAO-A (A6E5; 1/100) and then redeveloped with an antibody to MAO-B (B1C2; 1/100). Goat-anti-mouse antibody (IgG A-9917; Sigma, St Louis, MO) conjugated with horseradish peroxidase was used as the second antibody at a dilution of $1 / 2000$ in $8 \%$ nonfat milk to detect both signals.

SERT. Pellets from the centrifuged homogenized midbrain pontine blocks containing membrane-bound proteins were resuspended in $300 \mu \mathrm{l}$ of Tris $(10 \mathrm{mM})$ and EDTA $(1 \mathrm{mM})$, $\mathrm{pH} 7.2$, containing leupeptin $(1 \mu \mathrm{g} / \mathrm{ml})$, trypsin inhibitor (1 mg/ml), O-phenanthroline $(1 \mathrm{mM})$, iodoacetamide $(1 \mathrm{mM}), \operatorname{PMSF}(250 \mu \mathrm{M})$, and pepstatin A $(1 \mu \mathrm{M})$, and further homogenized with a hand-held pestle and mortar (Fisher Scientific, Pittsburgh, PA, USA). Samples containing $100 \mu \mathrm{g}$ of total protein from each animal were dissolved in $5 \%$ SDS containing $4 \% \quad \beta$-mercaptoethanol at $80^{\circ} \mathrm{C}$ for $15 \mathrm{~min}$ and heated at $90^{\circ} \mathrm{C}$ for $10 \mathrm{~min}$ before being loaded on a gel. The proteins were transferred onto a nitrocellulose blot, which was processed as described above, but developed with a mouse anti-human monoclonal antibody to SERT (ST51-2; MAb Technologies Inc., Stone Mountain, GA, USA; 1/500). Goat-anti-mouse antibody (IgG A-9917; Sigma, St Louis, MO; 1/2000) conjugated with horseradish peroxidase was used as a secondary antibody. The SERT signal was detected by exposing the blot to chemiluminescent film as above.

\section{Sample Arrangement on the Gels}

There were four animals in each treatment group. Comparisons of three to six treatments with a total of 12 to 24 samples required multiple gels. Therefore, the samples were loaded on each gel in a matched manner. That is, the order of loading the lanes from left to right was always a spayed animal and then an individual animal from each treatment group to be compared. This enabled a statistical covariance correction for gel-to-gel variation if needed. 
However, the gels were very consistent and covariance analysis was not required.

\section{Densitometric Analysis of Western Blotting Results}

The phosphoserine band corresponding to TPH, the TPH band, the SERT band, the MAO-A band, and the MAO-B band on the individual films were each captured using an XC-77 CCD video camera (Sony, Towada, Japan). The region of interest containing the sample band was marked. The image analysis program scans each lane and converts the size and intensity of each band to a peak. The NIH image then determines the area under the peak in arbitrary units.

\section{Hormone Assays}

A blood sample was obtained at necropsy for determination of serum levels of estrogen and progesterone. The sample was allowed to clot, centrifuged for separation of serum, and assayed for estrogen and progesterone utilizing a Roche Diagnostics 2010 Elecsys assay instrument (Basil, Switzerland) in the Endocrine Service Laboratory of ONPRC. Each assay had been validated for macaque plasma in comparison with traditional RIAs. Interassay coefficients of variation were less than $10 \%$ for each assay.

\section{Statistical Analysis}

Multiple group comparisons were analyzed with ANOVA and differences between treatment groups were considered significant when $p<0.05$. Post hoc pairwise comparisons were obtained with Student-Newman-Keuls (SNK) test and differences between treatment groups were considered significant when $p<0.05$. All statistical analyses were conducted with the Prism Statistic Program (GraphPad, San Diego, CA).

\section{RESULTS}

As expected, the antibody to phosphoserine produced multiple bands. However, by overlapping each phosphoserine film with the corresponding TPH film, it was clear that one phosphoserine band represented phosphorylated TPH. Figure 1 contains a representative blot that was first developed with the antibody to phosphoserine (middle panel) and then redeveloped with the antibody to TPH (top panel). The phosphorylated TPH band was adjacent to another band that interfered with the scan and image analysis. Therefore, the adjacent band was erased prior to scanning. This yielded a clean band corresponding only to phosphorylated TPH, which in turn produced a peak appropriate for optical density determination (Figure 1, bottom panels). The SERT bands on a representative Western blot are illustrated in Figure 2. Figure 3 illustrates the results from a representative blot that was developed with the antibody to MAO-A (top) and then redeveloped with the antibody to MAO-B (middle). The MAO-A and MAO-B films were overlapped in the bottom panel to show the difference in migration.

Estrogen treatment for 1 mo caused a significant $150 \%$ increase in TPH, and estrogen supplemented with progesterone for 1 mo caused a significant $203 \%$ increase in TPH

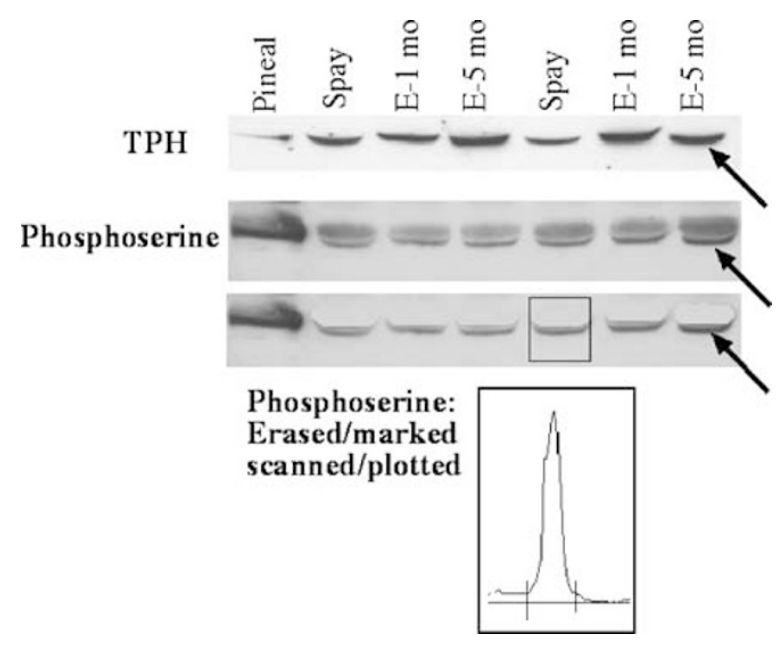

Figure I Digitized photographs of the autoradiographic films resulting from a representative Western blot developed first for phosphoserine and then redeveloped for TPH. Top and middle panels illustrate the bands exactly as they appear on the films. When the films are overlapped, it is clear that the bottom band on the phosphoserine film corresponds to TPH (arrows). In order to obtain a clear scan of the phosphorylated TPH band, the preceding unidentified phosphorylated band had to be erased. The lanes to be scanned were then marked, and a plot was generated. The area under the curve was considered the optical density and this was computed in arbitrary units. Each animal generated an independent value.

\section{SE R T}

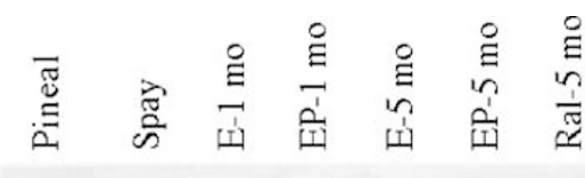

Figure 2 Digitized photograph of a typical autoradiographic film resulting from a representative Western blot developed for SERT. The pineal provided the positive control.

over spayed control animals (ANOVA $p<0.0001$; Figure 4, top). There was no difference in TPH protein between groups treated with estrogen alone or estrogen + progesterone. This confirms our earlier observation with additional animals (Pecins-Thompson et al, 1996). In addition, there was no significant difference in the signal corresponding to phosphorylated TPH (Figure 4, bottom) nor in the calculated ratio of phosphorylated TPH to TPH protein (data not illustrated).

Illustrated in Figure 5, top panel, there were similar and significant increases in TPH protein in the dorsal raphe region with 1 mo of estrogen treatment (148\%), and 5 mo of estrogen treatment $(164 \%)$ compared to the spayed control group (ANOVA $p<0.0001$ ). However, there was no difference in the signals corresponding to phosphorylated TPH (Figure 5, bottom), nor in the calculated ratio of phosphorylated TPH to TPH protein (not illustrated).

Next, there was a significant increase in TPH protein in the dorsal raphe region with 5 mo of estrogen alone (150\%), 5 mo of estrogen + progesterone $(122 \%)$, and 5 mo of raloxifene treatment (123\%) over spayed controls (ANOVA $p<0.0001$; Figure 6, top). There was no difference in TPH protein between all of the treated groups. The longer-term 

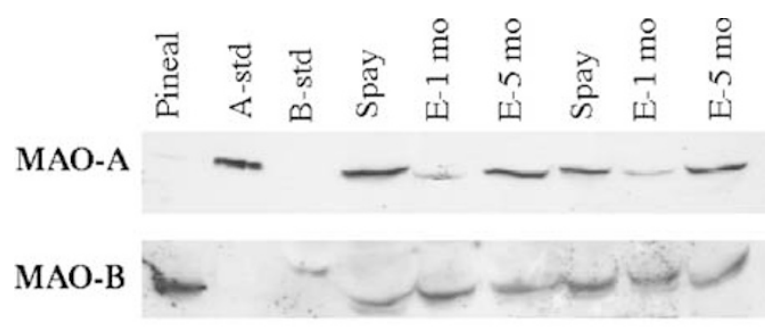

Film Overlay

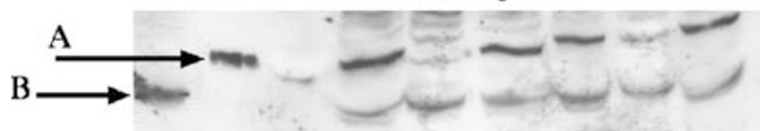

Figure 3 Digitized photographs of the autoradiographic films resulting from a representative Western blot developed first for MAO-A (top) and then redeveloped for MAO-B (middle). In the bottom panel, the films were overlayed to show that MAO-A and MAO-B migrate different distances on the gels. In the top panel, there is very little MAO-A present in the monkey pineal, but the purified MAO-A produced a robust signal and was used as the positive control lane. The bands migrating the same distance in the sample lanes were considered MAO-A. In the middle panel, the monkey pineal contains a very large amount of MAO-B that was used as the positive control since the purified MAO-B signal was weak and migrated slightly slower. The bands in the sample lanes that migrated the same distance as the single band in the pineal were considered MAO-B. By overlapping the films as shown in the bottom panel, it is apparent that the MAO-A and $\mathrm{MAO}-\mathrm{B}$ bands are separate and of sufficient difference in molecular weight, so that they migrate different distances. Thus, the antibodies bind to their respective cognate proteins.

progesterone treatment and raloxifene also increased the phosphorylation of $\mathrm{TPH}$, to 127 and $120 \%$, respectively (ANOVA, $p<0.002$; Figure 6 , bottom), as well as the ratio of phosphorylated TPH to TPH protein (not illustrated) compared to the spayed control group.

Neither estrogen alone nor estrogen + progesterone for 1 mo had any effect on SERT protein compared to the spayed control group (Figure 7, top). However, after 5 mo of estrogen or raloxifene treatment, SERT protein significantly increased by 137 and $126 \%$, respectively, over that observed in spayed control animals (ANOVA, $p<0.015$; Figure 7, bottom). SERT was elevated to $119 \%$ after treatment with estrogen and progesterone for $5 \mathrm{mo}$ (nearly significant).

Estrogen alone and estrogen + progesterone for $1 \mathrm{mo}$ significantly decreased MAO-A protein, to 55 and $44 \%$ respectively, compared to the spayed control group (ANOVA, $p<0.01$; Figure 8 , top). There was no difference between the treated groups, suggesting that the decrease was entirely due to estrogen. MAO-B protein expression was not significantly altered by estrogen alone, but the addition of progesterone to the estrogen regimen for 14 days significantly increased MAO-B by $203 \%$ over the spayed control group (ANOVA, $p<0.02$; Figure 8 , bottom panel).

In the next comparison, MAO-A was suppressed by $64 \%$ by 1 mo of estrogen treatment as observed previously, but there was no difference between the 5-mo estrogen treatment group and the spayed control group in the concentration of MAO-A (ANOVA, $p<0.006$; Figure 9, top). Neither 1 mo nor 5 mo of estrogen treatment had any effect on MAO-B expression in the dorsal raphe region (Figure 9, bottom).

The effect of supplementing the 5-mo estrogen regimen with progesterone on MAO-A and MAO-B concentrations
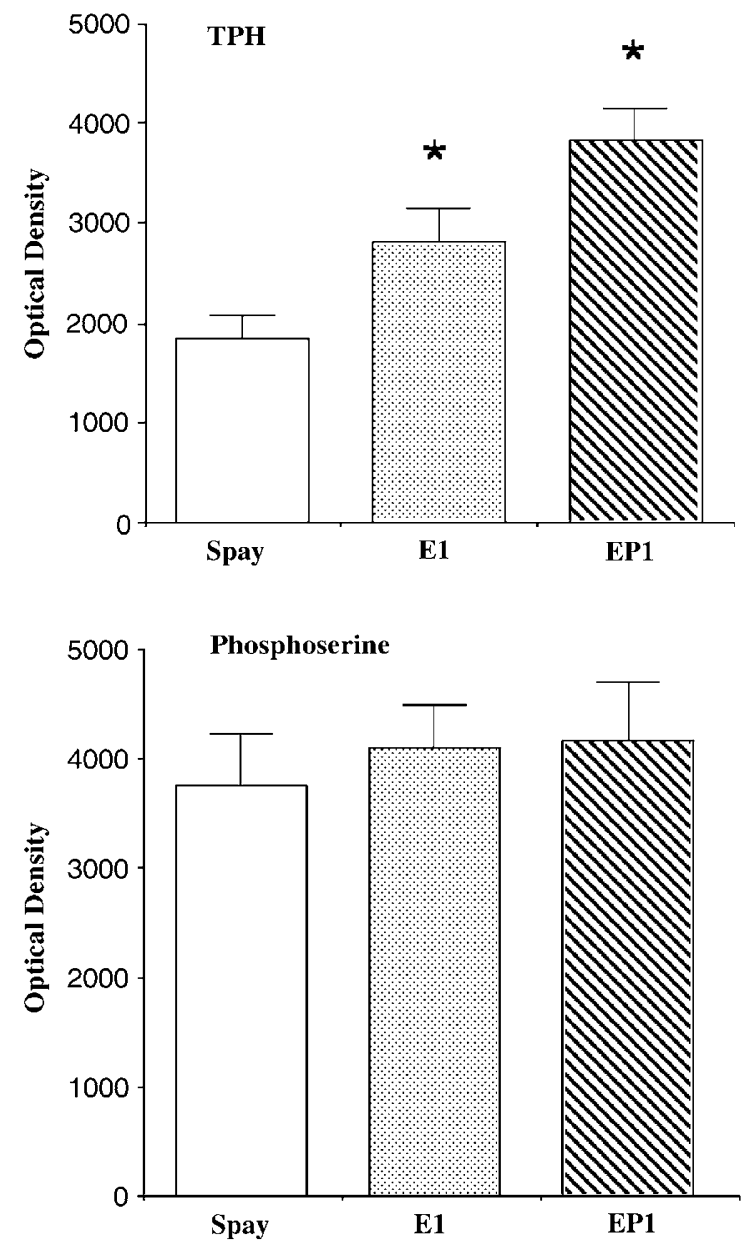

Figure 4 Histograms illustrating the mean \pm SEM ( $n=4$ per group) of TPH protein and phosphorylated TPH optical density in groups of monkeys that were spayed, treated with estrogen for one mo (EI), or treated with estrogen for I mo supplemented with progesterone for the last I 4 days of the treatment period (EPI). There was a significant difference in TPH protein with treatment (ANOVA, $p<0.000 \mathrm{I}$ ). EI - and EPI-treated groups were significantly higher than the spayed control group (SNK post hoc test, $p<0.00 \mathrm{l})$. There was no difference between the groups in the signal corresponding to phosphorylated TPH.

was then examined. MAO-A expression with 5 mo of estrogen alone or estrogen + progesterone treatment remained unchanged from the spayed control group (Figure 10, top). However, the addition of progesterone to the estrogen regimen for 5 mo increased MAO-B by $132 \%$ in the same manner seen with 1 mo of estrogen + progesterone treatment (ANOVA, $p<0.03$; Figure 10 , bottom and Figure 8, bottom).

Owing to the extra lanes required for purified MAO-A and MAO-B on the gels, MAO-A and MAO-B were examined in the 5-mo raloxifene group compared to the 5-mo estrogenonly group and the spayed control group in a separate experiment. Neither 5 mo of estrogen alone nor 5 mo of raloxifene had any effect on MAO-A or MAO-B expression (Figure 11, top and bottom, respectively).

Serum concentrations of estrogen and progesterone were measured by RIA in blood samples obtained at necropsy and the results are shown in Table 1. Estrogen treatment for 1- or 5-mo significantly elevated serum estrogen compared to the spayed control group and raloxifene-treated group 

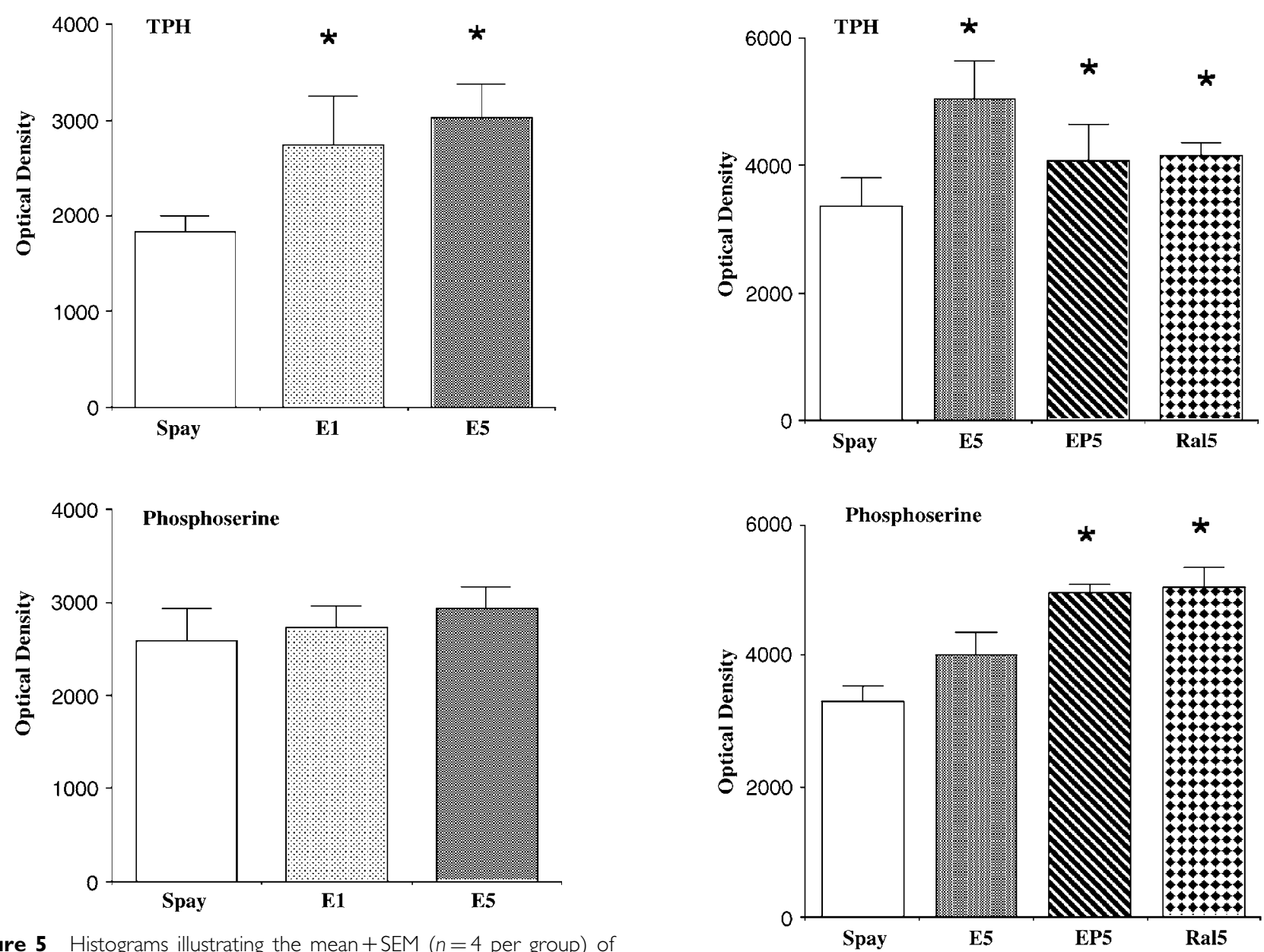

Figure 5 Histograms illustrating the mean \pm SEM ( $n=4$ per group) of TPH protein and phosphorylated TPH optical density in groups of monkeys that were spayed, treated with estrogen for one mo (EI), or treated with estrogen for $5 \mathrm{mo}$ (E5). There was a significant difference in TPH protein with treatment (ANOVA, $p<0.0 .000 \mathrm{I}$ ). EI- and E5-treated groups were significantly higher than the spayed control group (SNK post hoc test, $p<0.001)$. There was no difference between the groups in the phosphoserine signal corresponding to TPH.

( $p<0.05$, SNK post hoc pairwise comparison), but there was no difference in estrogen levels between the groups treated for 1 or 5 mo with estrogen plus or minus progesterone. Progesterone treatment for 1 or 5 mo significantly elevated serum progesterone compared to the other groups $(p<0.05$, SNK post hoc pairwise comparison), but there was no difference in progesterone levels with 1- or 5-mo treatment (Table 1).

\section{DISCUSSION}

The serotonin neural system projects to every area of the forebrain and regulates a wide range of neural outcomes from emotion to intellect to metabolism. Many of the serotonergic-governed functions and dysfunctions differ between men and women (Yonders et al, 1992; Williams et al, 1995; Bryant et al, 1999; Roof and Hall, 2000). To further our understanding of potential biological factors in affective disorders, we have studied the actions of ovarian hormones on aspects of serotonin neural function in spayed female rhesus macaques.

Figure 6 Histograms illustrating the mean \pm SEM ( $n=4$ per group) of TPH protein and phosphorylated TPH optical density in groups of monkeys that were spayed, treated with estrogen for 5 mo (E5), treated with estrogen + progesterone for 5 mo (EP5), or treated with raloxifene for 5 mo (Ral5). There was a significant difference in TPH protein with treatment (ANOVA, $p<0.000$ I). E5-, EP5-, and Ral5-treated groups had significantly higher TPH protein than the spayed control group (SNK post hoc test, $p<0.00$ I). There was also a significant difference between the groups in the signal corresponding to phosphorylated TPH (ANOVA, $p<0.002$ ). EP5- and Ral5-treated groups had significantly higher phosphoserine signal than the spayed control group (SNK post hoc test, $p<0.0$ I).

We previously showed that estrogen alters the expression of TPH-1, SERT, 5HT1A, and MAO-A genes in the dorsal raphe (Pecins-Thompson et al, 1996; Pecins-Thompson and Bethea, 1998; Pecins-Thompson et al, 1998; Gundlah et al, 2001a). We have recently found that TPH-2 mRNA is robustly expressed in the monkey raphe, and it is significantly increased by estrogen and estrogen + progesterone in a manner similar to TPH-1 (unpublished).

In this study, we extended our investigation to examine post-translational modification of TPH protein (Furukawa et al, 1993; Ichimura et al, 1995; Banik et al, 1997; Kuhn et al, 1997), corroborate our $\left[{ }^{3} \mathrm{H}\right]$ citalopram-binding results (Lu et al, 2003) with a direct measurement of SERT protein, and examine the expression of the two degradative proteins, $\mathrm{MAO}-\mathrm{A}$ and MAO-B. We also compared a longer treatment period to our standard 1 mo replacement regimen and determined the effect of a selective estrogen receptor (ER) 

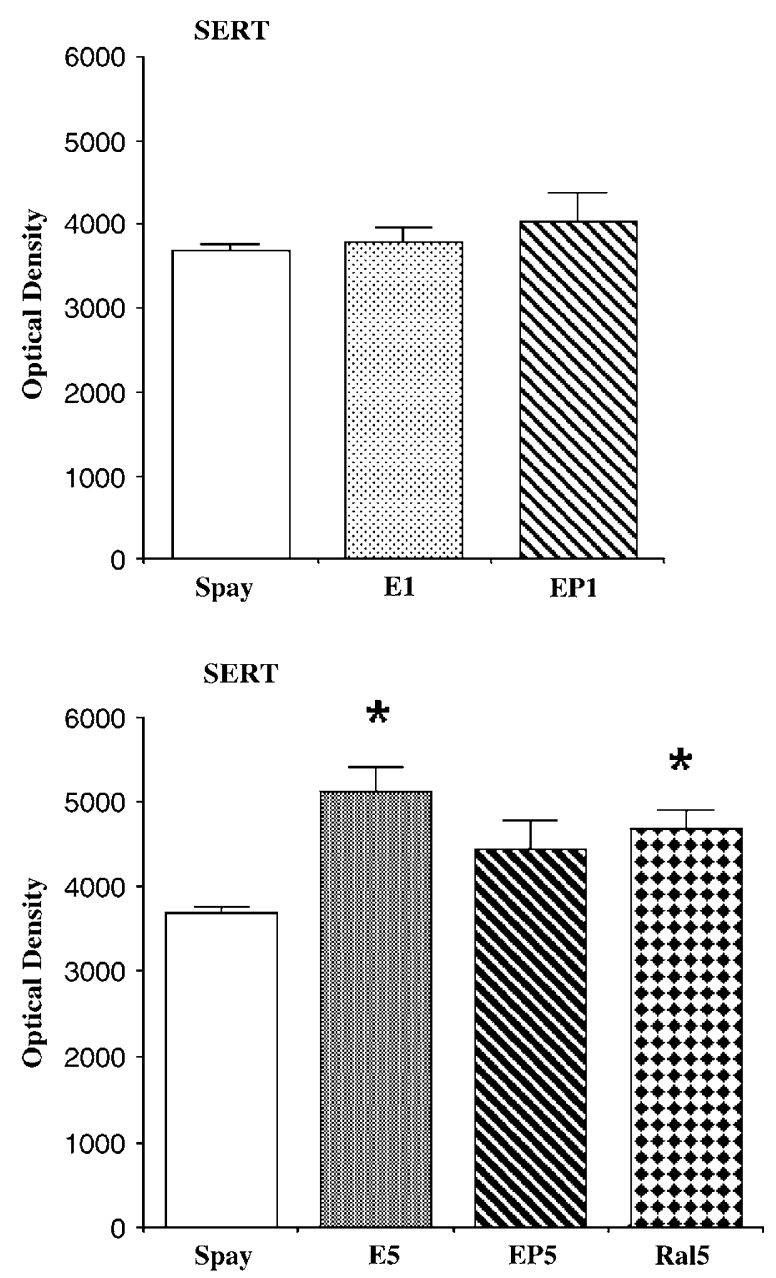

Figure 7 Top. Histogram illustrating the mean \pm SEM ( $n=4 /$ group) of SERT optical density in groups of monkeys that were spayed, treated with estrogen for I mo (EI), or treated with estrogen for I mo supplemented with progesterone for the last 14 days of the treatment period (EPI). There was no difference between the groups. (Bottom) Histogram illustrating the mean \pm SEM ( $n=4 /$ group) of SERT optical density in groups of monkeys that were spayed, treated with estrogen for 5 mo (E5), treated with estrogen + progesterone for 5 mo (EP5), or treated with raloxifene for $5 \mathrm{mo}$ (Ral5). There was a significant difference between the groups (ANOVA, $p<0.015)$. E5- and Ral5-treated groups had significantly higher SERT signal than the spayed control group (SNK post hoc test, $p<0.01$ and $<0.05$, E5 and Ral5, respectively).

modulator (SERM), raloxifene, on each parameter. Ultimately, the catalytic activities of these enzymes are required to show that the changes observed at the protein levels are functionally important.

At this time, the commercially available antibodies recognize both TPH-1 and TPH-2 proteins, so Western blot provides an indication of total TPH protein. With respect to $\mathrm{TPH}$, we confirmed our earlier observation that 1 mo of estrogen, with or without progesterone, increases TPH protein (Bethea et al, 2000). In addition, we show that 5 mo of estrogen, with or without progesterone, increases TPH protein in the same manner as 1 mo of estrogen. Hence, it appears that estrogen increases TPH gene and protein expression, and addition of progesterone has no effect on transcription or translation. TPH was phosphorylated regardless of treatment. However, with the longer progesterone
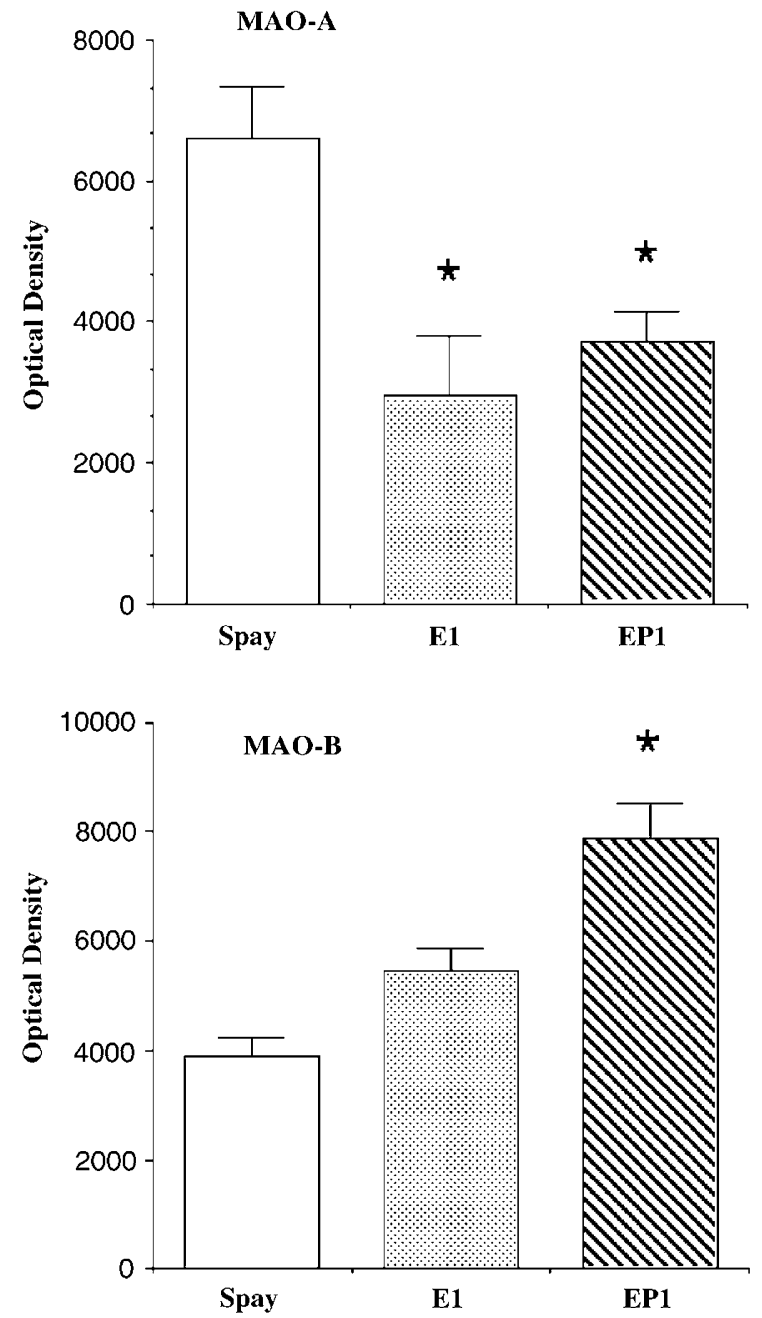

Figure 8 Histograms illustrating the mean \pm SEM ( $n=4$ per group) of MAO-A and MAO-B optical density in groups of monkeys that were spayed, treated with estrogen for I mo (EI), or treated with estrogen for I mo supplemented with progesterone for the last 14 days of the treatment period (EPI). There was a significant difference in MAO-A with treatment (ANOVA, $p<0.0 \mathrm{I}$ ). EI- and EPI-treated groups were significantly lower than the spayed control group (SNK posthoc test, $p<0.05$ ). There was also a significant difference in MAO-B with treatment (ANOVA, $p<0.002$ ). The EPI group had significantly higher MAO-B than the spayed control or EI treatment groups (SNK post hoc test, $p<0.0 \mathrm{I}$ ).

treatment there was an increase in the phosphorylation signal corresponding to TPH. This time-dependent mechanism warrants further investigation. Altogether, these data indicate that estrogen probably increases serotonin synthesis by a transcriptional mechanism and progesterone may increase serotonin synthesis by a post-translational mechanism.

The expression of SERT protein in the raphe region was consistent with our previous $\left[{ }^{3} \mathrm{H}\right]$ citalopram-binding study (Lu et al, 2003). That is, neither estrogen nor estrogen + progesterone for 1 mo had any effect on SERT protein levels. Nonetheless, after 5 mo of estrogen or 5 mo of raloxifene, SERT protein was significantly increased. This is consistent with our previous report that longer estrogenic treatment, that is, 2 years of equine estrogens, significantly increased SERT protein expression on a Western blot (Shively et al, 2003). In rats, estrogen induces an increase in 

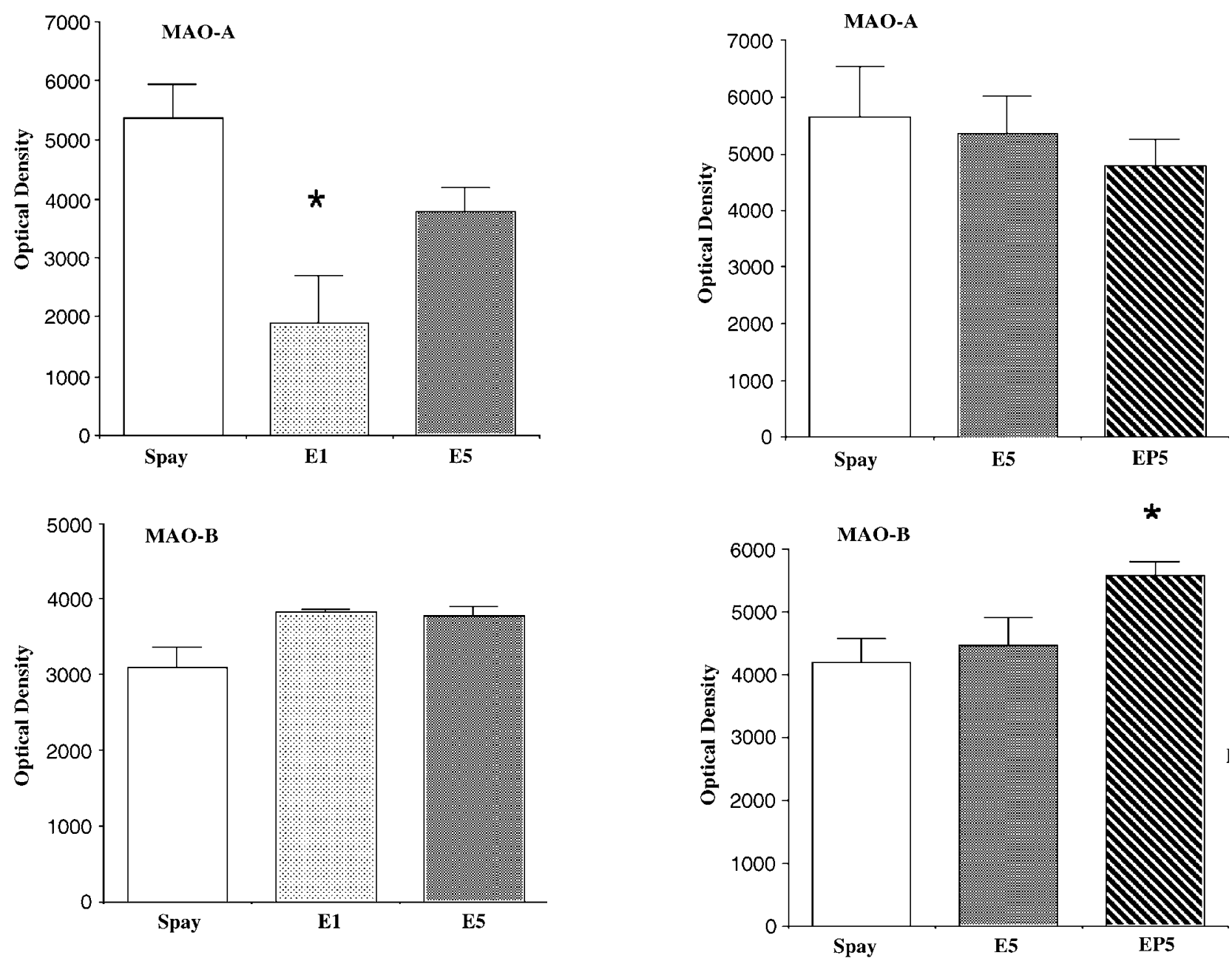

Figure 9 Histograms illustrating the mean \pm SEM ( $n=4$ per group) of MAO-A and MAO-B optical density in groups of monkeys that were spayed, treated with estrogen for I mo (EI), or treated with estrogen for 5 mo (E5). There was a significant difference in MAO-A with treatment (ANOVA, $p<0.006$ ). The El-treated group was significantly lower than the spayed control group or the E5-treated group (SNK post hoc test $p<0.01$ ). There was no difference between the groups in MAO-B.

SERT much faster (McQueen et al, 1996). Together, these data suggest that there is a time-dependent increase in SERT protein with estrogen treatment in primates, although the mRNA decreases. Hypothalamic $\left[{ }^{3} \mathrm{H}\right]$ citalopram binding increased before SERT protein in the raphe region, suggesting that SERT is trafficked to the forebrain regions first, with subsequent accumulation in the cell bodies. The increase in SERT protein accompanies the increase in TPH protein and presumably, with an increase in serotonin synthesis. We have speculated that these conditions produce an environment conducive to transporter reversal (Rudnick and Wall, 1993; Rothman and Baumann, 2002) that in turn would further elevate extracellular serotonin concentrations.

Our current understanding of the location and functionality of MAO-A and MAO-B suggests that one role is to reduce or eliminate amines that gain entry into neurons where they have no physiological function (Abell and Kwan, 2001). MAO-A prefers serotonin, but the highest level of MAO-A expression has been found in noradrenergic

Figure 10 Histograms illustrating the mean $\pm \operatorname{SEM}(n=4$ per group) of MAO-A and MAO-B optical density in groups of monkeys that were spayed, treated with estrogen for $5 \mathrm{mo}$ (E5), or treated with estrogen + progesterone for 5 mo (EP5). MAO-A was not different between the groups. There was a significant difference in MAO-B between the groups (ANOVA, $p<0.03$ ). MAO-B was significantly higher in the EP5treated group than in the spayed control group or in the E5-treated groups (SNK post hoc test, $p<0.05$ ).

neurons with low or moderate levels in dopamine or serotonin neurons, respectively. MAO-B prefers hydrophobic substrates such as phenylethylamine, but the expression of MAO-B is most abundant in serotonergic and histaminergic neurons (Westlund et al, 1985, 1988; Arai et al, 1997; Abell and Kwan, 2001).

MAO-A protein was decreased by 1 mo of estrogen alone, or with added progesterone, in the same manner as MAO-A mRNA in the dorsal raphe nucleus (Gundlah et al, 2001a). $\mathrm{MAO}-\mathrm{A}$ is thought to reside outside of serotonin neurons and the transient decrease in MAO-A with 1 mo estrogen treatment could lead to an increase in extracellular serotonin. However, after 5 mo of estrogen, estrogen + progesterone, or raloxifene treatment, MAO-A protein was no longer suppressed compared to spayed controls. With longer estrogen treatment, extracellular serotonin may be high enough to stimulate MAO-A production as a homeostatic mechanism. Serotonin, but not norepinephrine, neurons reportedly adapt to long-term MAO inhibitor treatment 

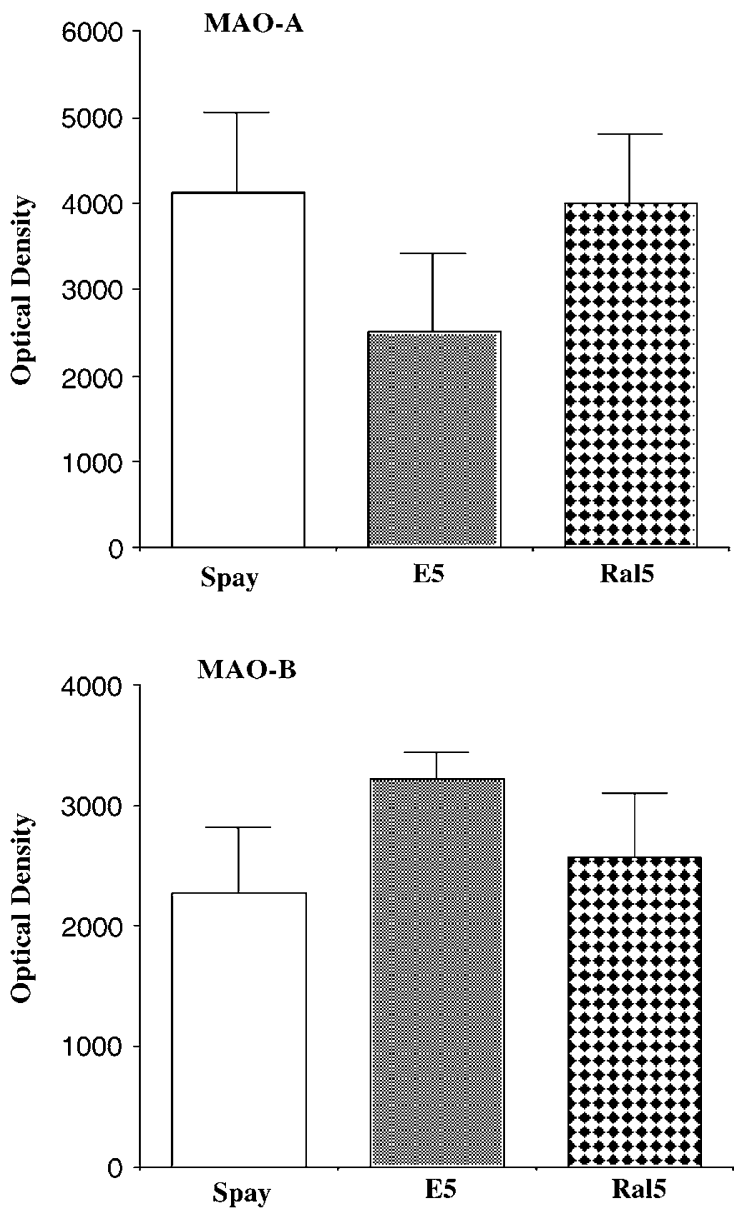

Figure I I Histograms illustrating the mean $\pm \operatorname{SEM}(n=4$ per group) of MAO-A and MAO-B optical density in groups of monkeys that were spayed, treated with estrogen for $5 \mathrm{mo}$ (E5), or treated with raloxifene for 5 mo (Ral5). Neither MAO-A nor MAO-B was different between the groups.

Table I Serum Concentrations of Estrogen and Progesterone (mean \pm SEM) in Blood Samples Obtained at Necropsy

\begin{tabular}{lcc}
\hline Groups & Estrogen $(\mathbf{p g} / \mathbf{m l})$ & Progesterone $(\mathbf{n g} / \mathbf{m l})$ \\
\hline Spayed $(n=6)$ & $14.83 \pm 0.91$ & $0.16 \pm 0.02$ \\
El month $(n=4)$ & $57.25 \pm 12.24^{\mathrm{a}}$ & $0.15 \pm 0.04$ \\
E5 month $(n=6)$ & $60.33 \pm 3.90^{\mathrm{a}}$ & $0.15 \pm 0.02$ \\
EPI month $(n=4)$ & $57.25 \pm 8.43^{\mathrm{a}}$ & $2.41 \pm 0.38^{\mathrm{b}}$ \\
EP5 month $(n=4)$ & $58.00 \pm 8.90^{\mathrm{a}}$ & $3.75 \pm 0.75^{\mathrm{b}}$ \\
Ral5 month $(n=4)$ & $14.33 \pm 0.67$ & $0.13 \pm 0.04$ \\
\hline
\end{tabular}

Estrogen treatment for I or 5 mo significantly elevated serum estrogen, but there was no difference in estrogen levels between the groups treated for I or 5 mo with estrogen alone or estrogen+progesterone. Progesterone treatment for I or 5 mo significantly elevated serum progesterone, but there was no difference in progesterone levels with I or 5 mo treatment

$\mathrm{EI}=$ treated with estrogen alone for I mo; $\mathrm{E5}=$ treated with estrogen alone for 5 mo; EP I = treated with estrogen for I mo supplemented with progesterone for the last 14 days of the estrogen treatment period; EP5 = treated with estrogen and progesterone for 5 mo; Ral $5=$ treated with raloxifene for 5 mo. ${ }^{a}$ Different from spayed and raloxifene-treated animals, SNK post hoc test $p<0.05$.

bDifferent from spayed, estrogen- and raloxifene-treated animals, SNK post hoc test $p<0.05$
(Blier and de Montigny, 1985). Perhaps, a similar mechanism is operational with long-term estrogen treatment.

In an earlier study, MAO-B gene expression in the dorsal raphe was not affected by 1 mo of hormone replacement (Gundlah et al, 2001a). In this study, estrogen for 1 or 5 mo also had no effect on MAO-B at the protein level in the raphe region. However, supplemental progesterone significantly increased MAO-B protein when administered for either 14 days or 5 mo. This suggests that progesterone increases translational efficiency of MAO-B mRNA in the raphe region. Although MAO-B prefers phenylethylamine (Fowler and Tipton, 1984), inhibition of MAO-B in cultured raphe neurons markedly elevated intracellular serotonin (Gu and Azmitia, 1993), suggesting that MAO-B can metabolize serotonin within the neuron. Indeed, this has been demonstrated, although the $K_{\mathrm{m}}$ is an order of magnitude higher than that of MAO-A (Fowler and Tipton, 1982). Along this line of reasoning, the progesteroneinduced increase in MAO-B could decrease intracellular serotonin. Since this would oppose the other actions of the ovarian hormones, it may be a homeostatic mechanism to govern intracellular serotonin concentrations. It has also been proposed that MAO-B in this area degrades norepinephrine from the locus coeruleus (Arai et al, 1997). Along this line of reasoning, the progesterone-induced increase in MAO-B would reduce impinging noradrenergic stimulation.

Continued effort toward understanding the actions of estrogen in the CNS are essential, but with the recognition that for the results to translate to clinical usefulness, the actions of estrogen will need to be duplicated by a ligand that does not have the peripheral risk profile. We have shown that serotonin neurons contain exclusively the beta isoform of the $\mathrm{ER}(\mathrm{ER} \beta)$, whereas the alpha isoform predominates in the breast and uterus (McLachlan et al, 1992; Nilsson and Gustafsson, 2000; Gundlah et al, 2001b). Hence, it is possible that a ligand with high affinity for ER $\beta$ could achieve estrogenic actions in the serotonin system without the peripheral risk profile of estradiol.

SERMs are ligands whose estrogenic properties vary from tissue to tissue depending on the isoform of ER utilized, as well as the coregulators recruited (Nagel et al, 2001; Katzenellenbogen and Katzenellenbogen, 2002; Kian Tee et al, 2004). Raloxifene is an SERM that has estrogenic-like effects in bone, but it is a high-affinity antagonist of ER $\alpha$ in other reproductive tissues (Buelke-Sam et al, 1998). Although raloxifene has poor penetration of the bloodbrain barrier, studies are accumulating, which indicate interesting estrogenic actions of raloxifene in the CNS. For example, raloxifene decreased fear and anxiety (Strickler et al, 2000), affected brain activation patterns during visual encoding (Neele et al, 2001), and had remarkable estrogenlike effects on neuroendocrine parameters in postmenopausal women (Florio et al, 2001). We previously showed that 1 mo of raloxifene increased TPH-1 gene expression in the dorsal raphe of spayed rhesus macaques (Bethea et al, $2002 \mathrm{~b}$ ) and in this study we find that TPH protein, TPH phosphorylation, and SERT protein are also increased after 5 mo of raloxifene. Combined with our report that primate serotonin neurons contain $\operatorname{ER} \beta$, these data suggest that raloxifene acts as an estrogen agonist at $\operatorname{ER} \beta$ in the context of a serotonin neuron and, in turn, it has positive effects on anxiety and neuroendocrine parameters in postmenopausal 
women. However, since raloxifene increased TPH phosphorylation, whereas estrogen alone for 5 mo did not, raloxifene may have actions beyond that of an $\operatorname{ER} \beta$ agonist.

In conclusion, estrogen for 1 or 5 mo increases TPH protein and longer-term progesterone supplementation appears to increase TPH phosphorylation, both of which would increase serotonin synthesis. Longer-term estrogen and raloxifene increased SERT protein, which in turn could increase transportation of serotonin. Short, but not longterm estrogen decreases MAO-A protein and progesterone supplementation was without effect. In contrast, MAO-B protein was unaffected by estrogen alone, but it was increased with short- or long-term progesterone supplementation. This may indicate a transient decrease in extracellular serotonin metabolism followed by either an increase in intracellular serotonin degradation or an increase in norepinephrine degradation. Raloxifene for 5 mo increased TPH protein and SERT protein in a manner like estrogen. Raloxifene also increased TPH phosphorylation like estrogen + progesterone, but it had no effect on MAO-B unlike estrogen + progesterone. Thus, estrogen, progesterone, and raloxifene have different, but overall enhancing effects on serotonin neurotransmission.

\section{ACKNOWLEDGEMENTS}

We thank the dedicated technicians of the Division of Animal Resources and the staff of the Departments of Surgery and Pathology, without whose help these studies would not have been possible. This work was supported by NIH Grants: MH62677 to CLB, NS24932 to CWA, U54 contraceptive Center Grant HD 18185, and RR000163 for the operation of ONPRC.

\section{REFERENCES}

Abell CW, Kwan SW (2001). Molecular characterization of monoamine oxidases A and B. Prog Nucleic Acid Res Mol Biol 65: 129-156.

Arai R, Kimura H, Maeda T (1997). Preferential localization of monoamine oxidase type A activity in neurons of the locus coeruleus and type B activity in neurons of the dorsal raphe nucleus of the rat: a detailed enzyme histochemical study. Brain Res 745: 352-356.

Banik U, Wang G-A, Wagner PD, Kaufman S (1997). Interaction of phosphorylated tryptophan hydroxylase with 14-3-3 proteins. J Biol Chem 272: 26219-26225.

Bethea CL, Lu NZ, Gundlah C, Streicher JM (2002a). Diverse actions of ovarian steroids in the serotonin neural system. Front Neuroendocrinol 23: 41-100.

Bethea CL, Mirkes SJ, Shively CA, Adams MR (2000). Steroid regulation of tryptophan hydroxylase protein in the dorsal raphe of macaques. Biol Psychiatry 47: 562-576.

Bethea CL, Mirkes SJ, Su A, Michelson D (2002b). Effects of oral estrogen, raloxifene and arzoxifene on gene expression in serotonin neurons of macaques. Psychoneuroendocrinology 27: 431-445.

Blier P, de Montigny C (1985). Serotoninergic but not noradrenergic neurons in rat central nervous system adapt to long-term treatment with monoamine oxidase inhibitors. Neuroscience 16: 949-955.

Bradford MM (1976). A rapid and sensitive method for the quantitation of microgram quantities of protein utilizing the principle of protein-dye binding. Anal Biochem 72: 248-254.
Bryant NL, Buchanan RW, Vladar K, Breier A, Rothman M (1999). Gender differences in temporal lobe structures of patients with schizophrenia: a volumetric MRI study. Am J Psychiatry 156: 603-609.

Buelke-Sam J, Bryant HU, Francis PC (1998). The selective estrogen receptor modulator, raloxifene: an overview of nonclinical pharmacology and reproductive and developmental testing. Reprod Toxicol 12: 217-221.

Celada P, Perez J, Alvarez E, Artigas F (1992). Monoamine oxidase inhibitors phenelzine and brofaromine increase plasma serotonin and decrease 5-hydroxyindoleacetic acid in patients with major depression: relationship to clinical improvement. J Clin Psychopharmacol 12: 309-315.

Chlebowski RT, Hendrix LL, Langer RD, Stefanick ML, Gass M, Lane D et al (2003). Influence of estrogen plus progestin on breast cancer and mammography in healthy postmenopausal women: the women's health initiative randomized trial. $J \mathrm{Am}$ Med Assoc 289: 3243-3253.

Clement Y, Chapouthier G (1998). Biological bases of anxiety. Neurosci Biobehav Rev 22: 623-633.

Dedeoglu A, Fisher A (1994). Cardiovascular activation by serotonergic stimulation: role of corticotropin-releasing factor. Am J Physiol 267: R859-R864.

Dumas S, Darmon MC, Delort J, Mallet J (1989). Differential control of tryptophan hydroxylase expression in raphe and in pineal gland: evidence for a role of translation efficiency. J Neurosci 24: 537-547.

Florio P, Quirici B, Casarosa E, Lombardi I, Luisi M, Genazzani AD et al (2001). Neuroendocrine effects of raloxifene hydrochloride in postmenopausal women. Gynecol Endocrinol 15: 359-366.

Fowler CJ, Tipton KF (1982). Deamination of 5-hydroxytryptamine by both forms of monoamine oxidase in the rat brain. J Neurochem 38: 733-736.

Fowler CJ, Tipton KF (1984). On the substrate specificities of the two forms of monoamine oxidase. J Pharm Pharmacol 36: 111-115.

Furukawa Y, Ikuta N, Omata S, Kamauchi T, Isobe T, Ichimura T (1993). Demonstration of the phosphorylation-dependent interaction of tryptophan hydroxylase with the 14-3-3 protein. Biochem Biophys Res Commun 194: 144-149.

Gibbs RB (2000). Effects of gonadal hormone replacement on measures of basal forebrain cholinergic function. Neuroscience 101: 931-938.

Gu XF, Azmitia EC (1993). Integrative transporter-mediated release from cytoplasmic and vesicular 5-hydroxytryptamine stores in cultured neurons. Eur J Pharmacol 235: 51-57.

Gundlah C, Lu NZ, Bethea CL (2001a). Ovarian steroid regulation of monoamine oxidase-A and -B mRNAs in the macaque dorsal raphe and hypothalamic nuclei. Psychopharmacology 160: 271-282.

Gundlah C, Lu NZ, Mirkes SJ, Bethea CL (2001b). Estrogen receptor beta $(\mathrm{ER} \beta)$ mRNA and protein in serotonin neurons of macaques. Mol Brain Res 91: 14-22.

Ichimura T, Uchiyama J, Kunihiro O, Ito M, Horigome T, Omata S et al (1995). Identification of the site of interaction of the 14-3-3 protein with phosphorylated tryptophan hydroxylase. J Biol Chem 270: 28515-28518.

Katzenellenbogen BS, Katzenellenbogen JA (2002). Defining the ' $S$ ' in SERMs. Science 295: 2380-2381.

Kerlikowske K, Miglioretti DL, Ballard-Barbash R, Weaver DL, Buist DS, Barlow WE et al (2003). Prognostic characteristics of breast cancer among postmenopausal hormone users in a screened population. J Clin Oncol 21: 4314-4321.

Kian Tee M, Rogatsky I, Tzagarakis-Foster C, Cvoro A, An J, Christy RJ et al (2004). Estradiol and selective estrogen receptor modulators differentially regulate target genes with estrogen receptors alpha and beta. Mol Cell Biol 15: 1262-1272.

Kuhn DM, Arthur Jr R, States JC (1997). Phosphorylation and activation of brain tryptophan hydroxylase: identification of serine-58 as a substrate site for protein kinase A. J Neurochem 68: 2220-2223. 
Lawrence KM, De Paermentier F, Cheetham SC, Crompton MR, Katona CL, Horton RW (1990). Brain 5-HT uptake sites, labelled with $\left[{ }^{3} \mathrm{H}\right]$ paroxetine, in antidepressant-free depressed suicides. Brain Res 526: 17-22.

Lesch K-P, Bengel D, Heils A, Sabol SZ, Greenberg BD, Petri S et al (1996). Association of anxiety-related traits with a polymorphism in the serotonin transporter gene regulatory region. Science 274: 1527-1531.

Lu NZ, Bethea CL (2002). Ovarian steroid regulation of 5HT1A receptor binding and $\mathrm{G}$ protein activation in female monkeys. Neuropsychopharmacology 27: 12-24.

Lu NZ, Eshleman AJ, Janowsky A, Bethea CL (2003). Ovarian steroid regulation of serotonin reuptake transporter (SERT) binding, distribution and function in female macaques. $\mathrm{Mol}$ Psychiatry 8: 353-360.

McLachlan JA, Newbold RR, Nelson KG, Korach KS (1992). Control of uterine epithelial growth and differentiation: implications for estrogen-associated neoplasia. In: Li J, Li S, Nandi R (eds). Hormonal Carcinogenesis. Springer: Verlag. pp 51-57.

McQueen JK, Wilson H, Dow RC, Fink G (1996). Oestradiol-17 $\beta$ increases serotonin transporter (SERT) binding sites and SERT mRNA expression in discrete regions of female rat brain. $J$ Physiol 495: 114.

Meneses A (1999). 5-HT system and cognition. Neurosci Biobehav Rev 23: 1111-1125.

Muldoon MF, Mackey RH, Williams KV, Korytkowski MT, Flory JD, Manuck SB (2004). Low central nervous system serotonergic responsivity is associated with the metabolic syndrome and physical inactivity. J Clin Endocrinol Metab 89: 266-271.

Nagel SC, Hagelbarger JL, McDonnell DP (2001). Development of an ER action indicator mouse for the study of estrogens, selective estrogen receptor modulators (SERMs), and xenobiotics. Endocrinology 142: 4721-4728.

Neele SJM, Rombouts SARB, Bierlaagh MA, Barkhof F, Scheltens P, Netelenbos JC (2001). Raloxifene affects brain activation patterns in postmenopausal women during visual encoding. J Clin Endocrinol Metab 86: 1422-1424.

Newhouse PA, Hancur CA, Naylor MR, Kelton M (2002). Estrogen administration blunts anticholinergic-induced psychomotor and attentional impairment in normal postmenopausal women. Biol Psychiatry 51S: 137S.

Nilsson S, Gustafsson JA (2000). Estrogen receptor transcription and transactivation: basic aspects of estrogen action. Breast Cancer Res 2: 360-366.

Pecins-Thompson M, Bethea CL (1998). Ovarian steroid regulation of 5HT1A autoreceptor messenger ribonucleic acid expression in the dorsal raphe of rhesus macaques. Neuroscience 89: 267-277.

Pecins-Thompson M, Brown NA, Bethea CL (1998). Regulation of serotonin re-uptake transporter mRNA expression by ovarian steroids in rhesus macaques. Mol Brain Res 53: 120-129.

Pecins-Thompson M, Brown NA, Kohama SG, Bethea CL (1996). Ovarian steroid regulation of tryptophan hydroxylase mRNA expression in rhesus macaques. J Neurosci 16: 7021-7029.
Roof RL, Hall ED (2000). Gender differences in acute CNS trauma and stroke: neuroprotective effects of estrogen and progesterone. J Neurotrauma 17: 367-388.

Rothman RB, Baumann MH (2002). Serotonin releasing agents. Neurochemical, therapeutic and adverse effects. Pharmacol Biochem Behav 71: 825-836.

Rudnick G, Wall SC (1993). The molecular mechanism of 'ecstasy' [3,4-methylenedioxy-methamphetamine (MDMA)]: serotonin transporters are targets for MDMA-induced serotonin release. Proc Natl Acad Sci 89: 1817-1821.

Schmidt PJ, Nieman L, Danaceau MA, Tobin MB, Roca CA, Murphy JH et al (2000). Estrogen replacement in perimenopause-related depression: a preliminary report. Am J Obstet Gynecol 183: 414-420.

Schneider LS, Small GW, Hamilton SH, Bystritsky A, Nemeroff CB, Meyers BS (1997). Estrogen replacement and response to fluoxetine in a multicenter geriatric depression trial. $\mathrm{Am} \mathrm{J}$ Geriatr Psychiatry 5: 97-106.

Schwartz S (1991). Women and depression: a Durkheimian perspective. Soc Sci Med 32: 127-140.

Shih JC, Chen K, Ridd MJ (1999). Monoamine oxidase: from genes to behavior. Annu Rev Neurosci 22: 197-217.

Shively CA, Laber-Laird K, Anton RF (1997). The behavior and physiology of social stress and depression in female cynomolgus monkeys. Biol Psychiatry 41: 871-882.

Shively CA, Mirkes SJ, Lu NZ, Henderson JA, Bethea CL (2003). Soy and social stress affect serotonin neurotransmission in primates. Pharmacogenom J 3: 114-121.

Strickler R, Stovall DW, Merritt D, Shen W, Wong M, Silfen SL (2000). Raloxifene and estrogen effects on quality of life in healthy postmenopausal women: a placebo-controlled randomized trial. Obstet Gynecol 96: 359-365.

Von Korff RW (1979). Monoamine Oxidase: Structure, Function and Altered Functions. Academic Press: New York.

Walther DJ, Peter J-U, Bashammakh S, Hortnagl H, Voits M, Fink $\mathrm{H}$ et al (2003). Synthesis of serotonin by a second tryptophan hydroxylase isoform. Science 299: 76.

Weissman MM, Olfson M (1995). Depression in women: implications for health care research. Science 269: 799-808.

Westlund KN, Denney RM, Kochersperger LM, Rose M, Abell CW (1985). Distinct monoamine oxidase A and B populations in primate brain. Science 230: 181-182.

Westlund KN, Denney RM, Rose RM, Abell CW (1988). Localization of distinct monoamine oxidase $\mathrm{A}$ and monoamine oxidase $\mathrm{B}$ cell populations in human brainstem. Neuroscience 25: 439-456.

Williams JBW, Spitzer RL, Linzer M, Kroenke K, Hahn SR, deGruy FV et al (1995). Gender differences in depression in primary care. Am J Obstet Gynecol 173: 654-659.

Wise PM, Dubal DB, Wilson ME, Rau SW, Bottner M (2001). Neuroprotective effects of estrogen - new insights into mechanisms of action. Endocrinology 142: 969-973.

Yonders KA, Kando JC, Cole JO, Glumentahl S (1992). Gender differences in pharmacokinetics and pharmacodynamics of psychotropic medication. Am J Psychiatry 149: 587-595. 